$\xi=-1$

\title{
Characteristics Analysis of Bio-Based Silica Extracted from Sarawak Palm Oil Waste
}

\author{
Nur Amalina Shairah Abdul Samat ${ }^{1}$, Siti Aishah Zulkafly ${ }^{1}$, Ummie Zulaikha Kamarul Jaman ${ }^{1}$, \\ Nur Syuhada Ahmad Zauzi ${ }^{1}$, Md Rezaur Rahman ${ }^{1}$, Rubiyah Baini ${ }^{1}$ \\ ${ }^{1}$ Department of Chemical Engineering and Energy Sustainability, Faculty of Engineering, Universiti Malaysia Sarawak \\ *Corresponding author E-mail: $\underline{\text { asnamalina@ unimas.my }}$
}

\begin{abstract}
Due to high production of palm oil, surplus quantities of palm oil wastes such as empty fruit bunches (EFB) and palm kernel shells (PKS) are generated. This study aims to analyze the characteristics of EFB and PKS ashes and their respective bio-silica content when combusted at different temperatures; $400^{\circ} \mathrm{C}, 600^{\circ} \mathrm{C}$ and $800^{\circ} \mathrm{C}$. Several tests like weight loss, colour and Fourier Transform Infrared (FTIR) analysis are conducted. EFB records higher weight loss compared to PKS for all combustion temperatures, thus implying less silica content compared to the later. Both wastes also show the highest weight loss at $99.20 \%$ and $98.51 \%$ respectively, when they are burnt at $800^{\circ} \mathrm{C}$ than those combusted at lower temperatures. This happens because more impurities evaporate at $800^{\circ} \mathrm{C}$, thus resulting in greater relative amount of silica in the ash. Colour analysis shows that the whiteness of both EFB and PKS ashes are the highest when combustion occurs completely at $800^{\circ} \mathrm{C}$, particularly at 71.56 and 42.40 respectively. Besides, FTIR analysis depicts distinct presence of $\mathrm{Si}-\mathrm{O}$ and $\mathrm{Si}-\mathrm{O}-\mathrm{Si}$ functional groups in both EFB and PKS ashes for all temperatures. It is also shown that combustion at $400^{\circ} \mathrm{C}$ are insufficient to remove impurities like hydroxyl groups, $\mathrm{CH}_{2}$ components and organic compounds.
\end{abstract}

Keywords: bio-based silica; colour; EFB; FTIR; PKS; weight

\section{Introduction}

Silica or silica gel, is generally used to absorb excess moisture and has put forefront for process industries, refrigerant drying, insulating glass industry, as well as packaging desiccants and desiccant powder. Manufacturing pure silica uses intensive energy by smelting quartz sand with sodium carbonate at $1300^{\circ} \mathrm{C}$ [1]. Huge amount of energy is needed to operate the furnace in order to extract pure silica which contributes to much loss of heat and deteriorates the environment. In recent years, many researchers were concentrated in producing environment-friendly products to replace fossil fuels with renewable energy sources using biomass feedstock [2]. In conjunction with the increasing environmental issues, several studies are conducted to convert biomass wastes into beneficial products, for instance, the extraction of bio-silica from biomass wastes. The main key of research is to discover the possible alternatives of raw materials that can be burnt at lower temperatures than quartz and are able to produce bio-based silica.

As Malaysia is one of the world's largest producer and exporter of palm oil and palm oil products, the production of surplus quantities of biomass wastes is ample. Approximately 4 million tonnes of palm oil wastes are produced per year [3]. In the palm oil mills, only $10 \%$ of the fresh fruit bunches consists of palm oil, while the remaining $90 \%$ are discarded as wastes. On an average basis, 1 tonne of crude palm oil can be generated from 5 tonnes of fresh fruit bunches (FFB) [4]. Several researches on silica extraction from agricultural products, mainly rice husk ashes, have been done such as studies by Majumder et al. [5], Prasad and Pandey [6] and Della et al. [7]. However, limited study was found on the effects of temperature on the properties of the silica in the palm oil wastes. Therefore, in this research, the properties of bio-based silica extracted from palm oil empty fruit bunch (EFB) and palm kernel shell (PKS) that are heated at temperatures of $400^{\circ} \mathrm{C}$ to $800^{\circ} \mathrm{C}$ are investigated.

\section{Materials and Methods}

The raw materials used as samples in this research are the main wastes from palm oil industries, namely, empty fruit bunch (EFB) and palm kernel shell (PKS). They are collected from Kilang Sawit FELCRA Berhad Samarahan, Kota Samarahan.

\subsection{Sample Preparation}

Prior to the experiments, all sample materials are prepared via acid washing and oven dyring, as illustrated in Fig. 1. The samples are washed with $1 \mathrm{M}$ hydrochloric acid $(\mathrm{HCl})$ until $\mathrm{pH} 1$ solution is obtained, before being dried in the oven at $60^{\circ} \mathrm{C}$ for 24 hours. The dried samples are then burnt in a furnace for 6 hours at three different temperatures; $400^{\circ} \mathrm{C}, 600^{\circ} \mathrm{C}$ and $800^{\circ} \mathrm{C}$. The physical properties and functional groups of the ash samples are then analyzed.

\subsection{Physical Properties Analysis}

\subsubsection{Weight Loss Analysis}

Weight loss of samples after combustion is determined to observe its relationship with the silica content in the sample. To compute this, the basic formula for weight loss as shown in Eq. 1 is used in this research. 
Weight Loss $=\frac{\mathrm{W}_{1}-\mathrm{W}_{2}}{\mathrm{~W}_{1}} \times 100 \%$

where $\mathrm{W}_{1}$ and $\mathrm{W}_{2}$ refer to the weights of the sample before and after combustion process respectively.

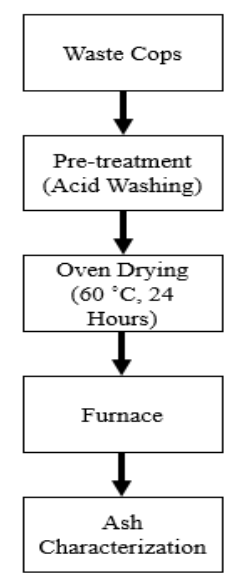

Fig. 1: Flowchart of sample preparation and analysis

\subsubsection{Colour Analysis}

The colour of the sample ash produced after combustion in the furnace is analyzed to determine the relative silica content in both sample ashes. According to Della et al. [7], the colour of the ash indicates the completeness of the combustion process. White ashes are produced only after complete combustion of samples occurs, as metallic impurities are removed effectively. Faizul et al. [1] also stated that incomplete combustion at low temperatures produces black or grey ash which is detected as inorganic impurities and unburned carbon amounts. Hence, high amount of silica is obtained when a white-coloured ash is produced.

To conduct colour analysis, the pixel data of the ash image is extracted using MATLAB in the form of RGB color space. The RGB color space is then converted into Lab color space whereby the value of Lab is then used to calculate the whiteness of sample using Eq. 2 [8]

$\mathrm{WI}=100-\sqrt{\left(100-\mathrm{L}^{*}\right)^{2}+\mathrm{a}^{*^{2}+\mathrm{b}^{* 2}}}$

where ' $L$ ' represents lightness while ' $a$ ' and ' $b$ ' represent redness $(+)$ or greenness (-), and yellowness (+) or blueness (-) respectively.

\subsection{Functional Properties Analysis}

The functional groups of samples are important to determine the characteristics of the materials. Fourier Transform Infrared (FTIR) analysis is performed with ten number of scans, using FTIR machine by Shimadzu FTIR Spectrometer (MODEL: IRAFFINITY$1)$.

\section{Results and Discussion}

The section discusses on the results of three analysis which will help in achieving the objectives of this study. They include weight loss, colour and Fourier Transform Infrared (FTIR) analysis.

\subsection{Weight Loss Analysis}

The main procedure in producing an active bio-silica from palm oil waste ash is the heat treatment. This procedure is vital as it can minimise the carbonaceous materials and undesirable components present in the ash samples, thus increases the relative amount of bio-silica in the samples. Table 1 illustrates the weight loss in the samples after 6 hours of calcination process.

Table 1: Weight loss of EFB and PKS after 6 hours of calcination process

\begin{tabular}{cccc}
\hline Sample & Before $(\mathrm{g})$ & After $(\mathrm{g})$ & Weight Loss $(\%)$ \\
\hline EFB 800 & 35.00 & 0.28 & 99.20 \\
EFB 600 & 35.00 & 0.39 & 98.89 \\
EFB 400 & 35.00 & 0.56 & 98.40 \\
PKS 800 & 170.00 & 2.54 & 98.51 \\
PKS 600 & 170.00 & 5.97 & 96.49 \\
PKS 400 & 170.00 & 8.23 & 95.16 \\
\hline
\end{tabular}

Based on Table 1, EFB records higher weight loss percentage compared to PKS at all combustion temperatures. It is as well observed that the weight loss of EFB and PKS burnt at $800^{\circ} \mathrm{C}$ are the highest compared to that burnt at lower temperatures of $400^{\circ} \mathrm{C}$ and $600^{\circ} \mathrm{C}$. Besides, greater weight loss of samples indicates lower amount of $\mathrm{Si}$ available in the ash. Instead, the ash contains more organic components, water formed by reactions and volatile compounds, which will evaporate at high temperatures due to the decomposition of hemicellulose and lignin found in the crops [3]. The remaining ash should mostly consist of silica which is a noncombustible element. Hence, crops that have lower weight loss have higher silica content. In this case, PKS ash has slightly more silica compared to the ash of $\mathrm{EFB}$, hence, indicating that more bio-based silica can be extracted from PKS than from EFB.

\subsection{Colour Analysis}

Table 2 tabulates the whiteness of EFB and PKS waste ashes computed using MATLAB. It is shown that EFB waste ash has the highest whiteness of 71.56 when combusted at high combustion temperature of $800^{\circ} \mathrm{C}$, followed by the lower temperatures of $600^{\circ} \mathrm{C}$ and $400^{\circ} \mathrm{C}$ with whiteness of 60.93 and 17.22 respectively. Similar trend is as well observed for PKS waste ashes, whereby it records the highest whiteness of 42.40 at $800^{\circ} \mathrm{C}$ and lower whiteness of 37.09 and 17.29 at $600^{\circ} \mathrm{C}$ and $400^{\circ} \mathrm{C}$ respectively. This, therefore, indicates that highest amount of silica is present in both palm oil waste ashes produced at $800^{\circ} \mathrm{C}$.

Table 2: Whiteness of EFB and PKS waste ashes

\begin{tabular}{ccccc}
\hline Sample & $\mathrm{L}^{*}$ & $\mathrm{a}^{*}$ & $\mathrm{~b}^{*}$ & Whiteness \\
\hline EFB 800 & 71.71 & -2.51 & 1.42 & 71.56 \\
EFB 600 & 61.08 & -1.51 & 3.03 & 60.93 \\
EFB 400 & 17.58 & 1.27 & -7.66 & 17.22 \\
PKS 800 & 42.55 & -0.60 & -4.05 & 42.40 \\
PKS 600 & 37.35 & 0.48 & -5.73 & 37.09 \\
PKS 400 & 17.70 & -0.27 & -8.19 & 17.29 \\
\hline
\end{tabular}

\subsection{FTIR Analysis}

Fourier Transform Infrared (FTIR) is used to investigate the presence of the major functional group in the samples. The most important functional group in this study is the predominant absorbance peak of $\mathrm{Si}-\mathrm{O}-\mathrm{Si}$ asymmetric band stretching vibration which is between $1050 \mathrm{~cm}^{-1}$ and $1200 \mathrm{~cm}^{-1}$ [9] and the corresponding stretch at around $750 \mathrm{~cm}^{-1}$ to $864 \mathrm{~cm}^{-1}$ [10]. Besides, the intense peak in the range of $450 \mathrm{~cm}^{-1}$ to $470 \mathrm{~cm}^{-1}$ corresponds to the $\mathrm{Si}-\mathrm{O}$ asymmetric bending vibration of $\mathrm{Si}-\mathrm{O}-\mathrm{Si}$ bond while peak between $2800 \mathrm{~cm}^{-1}$ and $3000 \mathrm{~cm}^{-1}$ represents the original organic compounds found in the crops [9]. The surface $-\mathrm{OH}$ groups of $\mathrm{Si}-\mathrm{OH}$ is indicated by the broad band from $1620 \mathrm{~cm}^{-1}$ to $1700 \mathrm{~cm}^{-1}$ as well as $3512 \mathrm{~cm}^{-1}$ and $3851 \mathrm{~cm}^{-1}$ [11]. Meanwhile, peak within the range of $2308 \mathrm{~cm}^{-1}$ to $2596 \mathrm{~cm}^{-1}$ indicates a $\mathrm{CH}_{2}$ bond where the wavelength of the peaks decreases as temperature increases [11].

Fig. 2 and Fig. 3 illustrate the IR spectra for EFB and PKS ashes combusted at $400^{\circ} \mathrm{C}, 600^{\circ} \mathrm{C}$ and $800^{\circ} \mathrm{C}$, whilst Table 3 summarizes the peak data obtained for both samples. Based on Table 3, both samples have absorbances in the range of $450 \mathrm{~cm}^{-1}$ to $470 \mathrm{~cm}^{-1}$ and $750 \mathrm{~cm}^{-1}$ to $864 \mathrm{~cm}^{-1}$, at all combustion temperatures, which correspond to the $\mathrm{Si}-\mathrm{O}$ asymmetric bending vibration of $\mathrm{Si}-\mathrm{O}-\mathrm{Si}$ bond and $\mathrm{Si}-\mathrm{O}-\mathrm{Si}$ asymmetric band stretching vibration respectively. 
Both samples also display peaks within the band of $1050 \mathrm{~cm}^{-1}$ to $1200 \mathrm{~cm}^{-1}$, which also indicates the presence of Si-O-Si asymmetric band stretching vibration in the sample waste ashes. These results imply that both palm oil waste (EFB and PKS) ashes have silica content for all tested combustion temperatures and hence, suggest that bio-based silica can be extracted from these wastes.

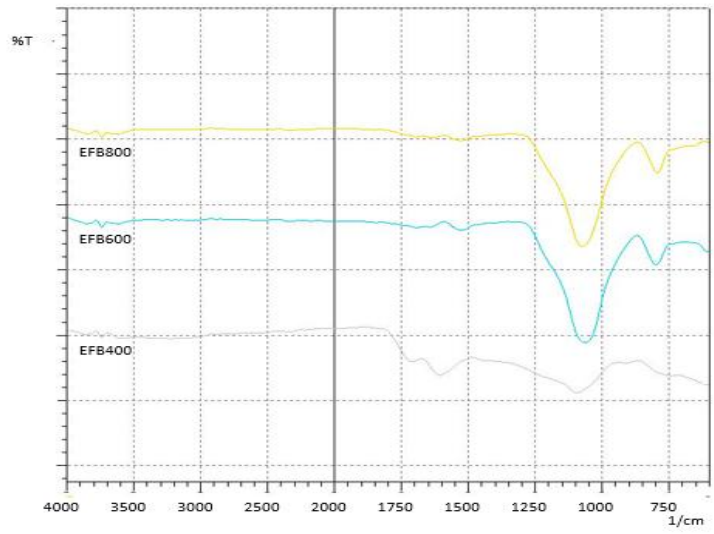

Fig. 2: FTIR spectra of EFB

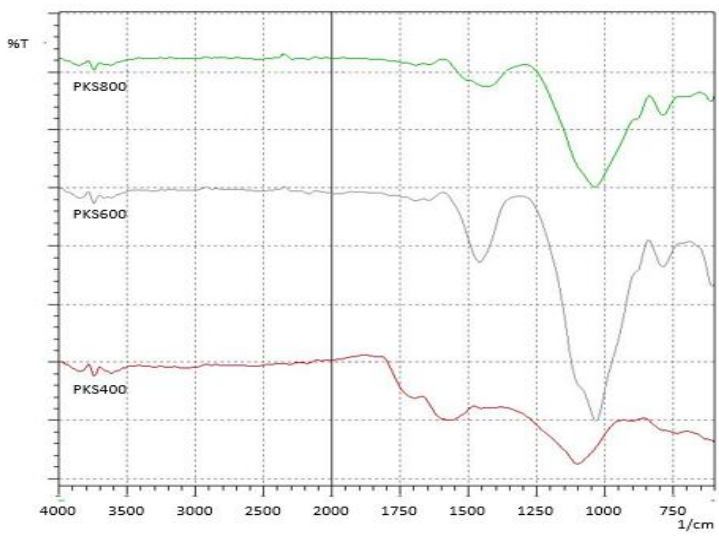

Fig. 3: FTIR spectra of PKS

Table 3: Summary peaks $\left(\mathrm{cm}^{-1}\right)$ of EFB and PKS waste ashes

\begin{tabular}{cccc}
\hline \multirow{2}{*}{ Sample } & \multicolumn{3}{c}{ Peak $\left(\mathrm{cm}^{-1}\right)$} \\
\cline { 2 - 4 } & 800 & 600 & 400 \\
\hline \multirow{2}{*}{ EFB } & 447.49 & 466.77 & 474.49 \\
& 792.74 & 798.53 & 744.52 \\
& 1076.28 & 1064.71 & 1097.5 \\
& - & - & 1686.79 \\
& - & - & 2320.37 \\
& - & - & 2823.79 \\
PKS & - & - & 2889.37 \\
& - & - & 3608.81 \\
& 774.49 & 457.13 & 464.84 \\
& 1035.77 & 788.89 & 781.17 \\
& - & 1033.85 & 1103.28 \\
& - & - & 2308.79 \\
& - & - & 2883.58 \\
& - & - & 2999.31 \\
& & - & 3819.06 \\
\hline
\end{tabular}

On the other hand, hydroxyl groups are observed only in the waste ashes produced at $400^{\circ} \mathrm{C}$ (EFB 400 and PKS 400) such that the peaks emerge within the ranges of $1620 \mathrm{~cm}^{-1}$ to $1700 \mathrm{~cm}^{-1}$ as well as $3512 \mathrm{~cm}^{-1}$ to $3851 \mathrm{~cm}^{-1}$. This implies that $-\mathrm{OH}$ groups completely evaporate at higher temperatures of $600^{\circ} \mathrm{C}$ and $800^{\circ} \mathrm{C}$. Apart from that, organic compounds and $\mathrm{CH}_{2}$ bonds, which correspond to the bands of $2308 \mathrm{~cm}^{-1}$ to $2596 \mathrm{~cm}^{-1}$ and $2800 \mathrm{~cm}^{-1}$ to $3000 \mathrm{~cm}^{-1}$ respectively, are also found to remain in both EFB and PKS ashes burnt at $400^{\circ} \mathrm{C}$. These results show that combustion process of EFB and PKS wastes at $600^{\circ} \mathrm{C}$ is sufficient to remove the hydroxyl groups, $\mathrm{CH}_{2}$ compounds and other organic components, thus, increases the relative content of silica in both sample waste ashes.

\section{Conclusion}

This research compares the characterization results of two palm oil waste ashes, namely EFB and PKS, which are burnt in a furnace at three different temperatures; $400^{\circ} \mathrm{C}, 600^{\circ} \mathrm{C}$ and $800^{\circ} \mathrm{C}$. Three investigations are conducted which include weight loss, colour and FTIR analysis. The results show that EFB has greater weight loss for all combustion temperatures compared to PKS. It is also proven that EFB and PKS wastes, burnt at $800^{\circ} \mathrm{C}$, display the greatest weight loss than that combusted at lower temperatures of $400^{\circ} \mathrm{C}$ and $600^{\circ} \mathrm{C}$. As greater weight loss of samples indicates lower amount of $\mathrm{Si}$ available in the ash, it is determined that EFB ash has slightly less silica compared to the ash of PKS. Besides, colour analysis proves that the greatest whiteness of ash is observed when EFB and PKS wastes are completely burnt at $800^{\circ} \mathrm{C}$, which therefore, indicates the highest relative content of silica in these waste ashes. Furthermore, FTIR analysis shows distinct presence of Si-O and $\mathrm{Si}-\mathrm{O}-\mathrm{Si}$ functional groups in both EFB and PKS samples combusted at all temperatures, while other impurities, such as hydroxyl groups, $\mathrm{CH}_{2}$ components and organic compounds, remain in the ashes when samples are combusted at $400^{\circ} \mathrm{C}$.

\section{Acknowledgement}

The authors would like to acknowledge Universiti Malaysia Sarawak (UNIMAS) for providing the technical and financial assistance to this work. [Research Grant : Special Short Term Grant (SpSTG) - F02/SpSTG/1371/16/13]

\section{References}

[1] Faizul CP, Abdullah C \& Fazlul B (2013), Extraction of silica from palm ash using citric acid leaching treatment : Preliminary result. Advanced Materials Research 795, 701-706.

[2] Ben-Iwo J, Manovic V \& Longhurst P (2016), Biomass resources and biofuels potential for the production of transportation fuels in Nigeria. Renewable and Sustainable Energy Reviews 63, 172-192.

[3] Bakar RA, Yahya R \& Gan SN (2016), Production of high purity amorphous silica from rice husk. Procedia Chemistry 19, 189-195.

[4] Sarawak Energy (2016), Palm Oil Mill Effluent, Retrieved from http://www.sarawakenergy.com.my/index.php/r-d/biomassenergy/palm-oil-mill-effluent.

[5] Majumder CB, Sharma M \& Soni G (2014), A simple nonconventional method to extract amorphous silica from rice husk. Bioresource Technology.

[6] Prasad R \& Pandey M (2012), Rice husk ash as a renewable source for the production of value added silica gel and its application : An overview. Bulletin of Chemical Reaction Engineering \& Catalysis 7 (1), 1-25.

[7] Della VP, Kuhn I \& Hotza D (2002), Rice husk ash as an alternate source for active silica production. Materials Letters 57(4), 818821.

[8] Mustafa Kamal M, Baini R, Mohamaddan S, Selaman OS, Ahmad Zauzi NS, Rahman MR, Abdul Rahman N, Chong KH, Atan MF \& Abdul Samat NAS (2016), Effect of temperature to the properties of sago starch. IOP Conf. Series: Materials Science and Engineering 206.

[9] Geetha D, Ananthiand A \& Ramesh PS (2016), Preparation and characterisation of silica material from rice husk ash - An economical viable method. Research \& Reviews : Journal of Pure and Applied Physics 4(3), 20-26.

[10] Patil R, Dongre R \& Meshram J (2014), Preparation of silica powder from rice husk. Journal of Applied Chemistry, 26-29.

[11] Premaratne WAPJ, Priyadarshana WMGI, Gunawardena SHP \& De Alwis AAP (2013), Synthesis of nanosilica from paddy husk ash and their surface functionalization. Journal of Science University of Kelaniya 8, 33-48. 